\title{
0 DESAPARECIMENTO FORÇADO E A ABERTURA PARA A DEMOCRACIA NA AMÉRICA LATINA
}

\section{Douglas Tarcísio Reis da Silva}

Advogado, mestre em Direitos Humanos pela Universidade Federal do Pará (mobilidade em Direito Internacional na Adam Mickiewicz University - Polônia). Especialista em Direito do Trabalho pela UNIDERP.

\section{Resumo}

0 presente estudo se volta ao fenômeno do desaparecimento forçado de pessoas e a sua relação com 0 processo de abertura para a democracia nos países latino-americanos. Objetiva-se entender o papel da referida prática dentro do aparelho repressivo dos Estados totalitários, bem como identificar as vítimas de tal violação. Após isso, analisam-se os desafios enfrentados pelos organismos internacionais para a erradicação do desaparecimento forçado dentro dos três momentos históricos: ditadura, transição para a democracia e consolidação das democracias recentes. Dessa forma, busca-se um melhor entendimento sobre o fenômeno do desaparecimento forçado na América Latina, e também a relação entre a sua erradicação e o processo de abertura e consolidação das democracias na região.

\section{Palavras-chave}

Desaparecimento forçado. Ditadura. Justiça de transição. Sistema Interamericano.

\section{THE ENFORCED DISAPPEARANCE AND THE OPENING FOR DEMOCRACY IN LATIN AMERICA}

\section{Abstract}

This study focus on forced disappearance phenomenon of people and their relationship with the opening to democracy in Latin American countries. The objective is to understand the role of the practice within the repressive apparatus of the totalitarian states, as well as identify the victims of such violation. After that, it analyzes the challenges faced by international organizations in the process of elimination of forced disappearance within three historical moments: dictatorships, transition to democracy and consolidation of new democracies. This way, it seeks a better understanding of the phenomenon of enforced disappearance in Latin America as well as the relationship between the eradication of this practice and the process of opening and consolidation of the democracies in the region.

\section{Keywords}

Enforced disappearance. Dictatorship. Transitional justice. Inter-American system. 


\section{Sumário}

1 Introdução. 20 fenômeno do desaparecimento forçado. 30 desaparecimento forçado e as ditaduras na América Latina. 40 desaparecimento forçado e a transição democrática na américa latina. 50 desaparecimento forçado e a consolidação das democracias na américa latina. 6 Considerações finais. 7 Referências. 


\section{INTRODUÇÃO}

Nos dias atuais, por meio da discussão na doutrina e jurisprudência internacionais, bem como pelo empenho de órgãos de direitos humanos e ONGs voltadas para a proteção das vítimas e seus familiares, se tem uma delimitação mais clara do que se entende por desaparecimento forçado e das condutas que caracterizam essa violação.

Tal fenômeno, em razão da sua complexidade - tanto em relação ao contexto em que é realizado quanto em relaçáo à pluralidade de condutas - suscita muitas questóes a serem tratadas.

O desaparecimento forçado, da forma que se deu no contexto ditatorial da América Latina, apresenta características singulares. A maneira como foi empregado dentro dos governos ditatoriais e as vítimas de tal prática que seguem um modus operandi desencadeado nessa região, permitem a afirmação de um padrão de desaparecimento forçado latino-americano.

A análise da prática do desaparecimento não deve, todavia, se limitar ao período ditatorial, sob pena de um entendimento incompleto tanto do que representa quanto dos efeitos que atingem não somente as vítimas, mas a sociedade como um todo.

Dessa forma, uma análise sobre o contexto histórico, político e jurídico em torno dessa violação e sua relação com o Sistema Interamericano de Proteção dos Direitos Humanos, mostra-se essencial com o objetivo de compreender melhor seu papel dentro das ditaduras latino-americanas, bem como os desafios enfrentados para a sua erradicação.

O objetivo deste estudo pode ser alcançado por meio da divisão da análise da prática em três períodos: o período ditatorial, o período de transição para as democracias, e o período de consolidação das democracias recentes. Necessário se faz, porém, uma prévia análise do surgimento do desaparecimento forçado como política de Estado no momento histórico da Segunda Guerra.

Esclarece-se que não se busca aqui um estudo exaustivo, mas um debate sobre os principais temas relativos ao desaparecimento forçado, bem como os desafios enfrentados em cada período. 


\section{FENÔMENO DO DESAPARECIMENTO FORÇADO}

A ideia de desaparecimento não pode ser considerada nova. De fato remonta às guerras na Antiguidade, quando soldados acabavam por não retornarem das batalhas e seus corpos não eram encontrados. $\mathrm{E}$ foi em razão disso que, no século 19 , os soldados da guerra civil norte-americana passaram a ter, junto as suas vestimentas, uma identificação contendo seu nome, regimento e divisão no exército (Martin, 2002, p. 722).

Tal forma de identificação tornou-se obrigatória após a Primeira Guerra Mundial, conforme estabelecido na Conferência Internacional da Cruz Vermelha no ano de 1925 . Tem-se aqui uma das primeiras ações no sentido de reduzir os chamados missing in action.

Os desaparecimentos forçados, no entanto, somente passaram a ser conhecidos mundialmente durante a Segunda Guerra Mundial, especificamente com o Nacht und Nebel Erlass (Decreto Noite e Neblina), editado por Adolf Hitler em 7 de dezembro de 1941. Seu propósito era apreender as pessoas nos territórios ocupados pelo nazismo, fazendo com que elas desaparecessem sem deixar rastros, não sendo fornecida qualquer informaçáo sobre seu paradeiro aos familiares das vítimas (Vitkauskaitè-Meurice; Žilinskas, 2010, p. 198).

Um memorando do Alto Comando das Forças Armadas na Alemanha, à época, explicou os elementos básicos deste programa de contrainsurgência. Nele constava que membros suspeitos da resistência seriam julgados por tribunais militares apenas se a pena de morte fosse certa:

Em todos os outros casos, os presos deveráo ser transportados para a Alemanha secretamente, e posteriores análises sobre as infraçôes ocorrerão aqui; estas medidas terão um efeito dissuasor, porque:

A. o prisioneiro vai desaparecer sem deixar rastro,

1 Em tradução livre do inglês, significa "desaparecido em combate". Tal classificação é atribuída aos desaparecidos durante o serviço nas forças armadas. Estes podem ter sido mortos, feridos, se tornado prisioneiros de guerra, ou desertaram. Se falecidos, nem os seus restos mortais, tampouco túmulo foram identificados. 
B. nenhuma informação pode ser dada sobre o seu paradeiro ou seu destino (Memorando do Alto Comando das Forças Armadas para Escritório dos Países Estrangeiros. Dept. Abwehr, 2 de fevereiro de 1942).

Tal processo resultou no fato de que os prisioneiros praticamente desapareceram dos territórios ocupados, sendo seus paradeiros totalmente desconhecidos.

Wilhelm Keitel, que foi julgado, condenado e enforcado por, entre outros crimes seu papel na criação do decreto Noite e Neblina, explicou o propósito da prática de desaparecimentos em uma carta de apresentação anexa a este decreto:

O Führer é da seguinte opinião. Se esses crimes são punidos com pena de prisão, mesmo com trabalhos forçados por toda a vida, isso será encarado como um sinal de fraqueza. Intimidação eficiente e duradoura só pode ser conseguida por meio de pena de morte ou por medidas pelas quais os parentes do criminoso e a população náo sabem o destino do criminoso. Este objetivo é alcançado quando o criminoso é transferido para a Alemanha (Memorando do Alto Comando das Forças Armadas para Escritório dos Países Estrangeiros. Dept. Abwehr, 2 de fevereiro de 1942).

A detenção secreta prevista no Decreto tinha dois objetivos principais: em primeiro lugar, o indivíduo era afastado da proteção da lei. Esse ato coloca a vítima em uma situação de extrema vulnerabilidade, na medida em que lhe é retirada, nas palavras de Hannah Arendt (1989), o "direito a ter direitos".

Em sua obra "As origens do totalitarismo", a autora considera a exclusão da proteção legal da pessoa como um primeiro passo para o pleno domínio de um governo totalitário. Para ela, "o primeiro passo essencial no caminho do domínio total é morte da pessoa jurídica do homem. Por um lado, isso foi conseguido quando certas categorias de pessoas foram excluídas da proteção da lei” (Arendt, 1989, p. 497).

Em segundo lugar, e mais importante, a detenção secreta serviu como forma de gerar um estado de apreensão geral, conseguido mediante a intimidação e ansiedade causadas pelo sentimento de permanente incerteza da família em relação ao paradeiro da pessoa desaparecida. 
Observa-se aqui outra importância desse completo desaparecimento das vítimas para o mecanismo do domínio total nos casos em que o regime se defronta com a memória dos sobreviventes. Nessa lógica de dominação, o desaparecimento se mostra como algo mais eficaz do que a própria execução.

Nesse sentido, o método do homicídio resulta antiquado e ineficaz, na medida em que o assassino deixa para trás um cadáver e, embora tente apagar os traços da sua própria identidade, não pode apagar da memória dos que ficaram vivos a identidade da vítima. Assim, a materialidade de um cadáver náo gera tanta insegurança e apreensão quanto a incerteza da falta de informaçóes sobre a vítima desaparecida.

Com isso, nos países totalitários, todos os locais de detenção administrados pela polícia acabam por se constituir em verdadeiros "poços de esquecimento" (Arendt, 1989, p. 485), no qual as pessoas caem por acidente, sem deixar para trás os vestígios tão naturais de uma existência anterior, como um cadáver ou uma sepultura.

Foi utilizando-se dessa lógica que Hitler buscou aterrorizar as populaçóes dos territórios ocupados do Leste Europeu. O desaparecimento forçado era, então, a base de um projeto de eliminaçáo da resistência nesses lugares. O objetivo do Estado Nazista seria, em última análise, controlar os territórios ocupados por meio da criação de um estado de pânico.

Tais fatos levaram à consideração dos referidos desaparecimentos como crime de guerra em sede dos julgamentos do Tribunal Internacional de Nuremberg. Durante os argumentos finais da promotoria no Julgamento de Wilhelm Keitel, o promotor do Reino Unido, Hartley Shawcross, enfatizou a distinção do desaparecimento de presos, da sua execução ou detenção ilegal (Finucane, 2010, p. 177).

Shawcross citou a carta de Keitel (nota $n^{\circ}$ 5), a fim de destacar o fato de que a detençáo de prisioneiros sob circunstâncias em que se negaria qualquer informação no que diz respeito a sua sorte era, por si só, criminosa (Finucane, 2010, p. 176). O Tribunal considerou, no caso, que tal prática viola o artigo $46 \mathrm{da}$ 
Convenção de Haia de 1907, no qual está previsto que "a honra familiar, a vida das pessoas, a propriedade privada, assim como as convicçóes e práticas religiosas, devem ser respeitadas". ${ }^{2}$

Dessa forma, o Tribunal de Nuremberg condenou o Decreto Noite e Neblina como uma forma de violação dos direitos da pessoa desaparecida e dos familiares das vítimas. A inovação do programa reside justamente no dano causado às famílias, diferenciando-o, assim, dos homicídios e sequestros.

No que diz respeito ao reconhecimento do desaparecimento forçado como um crime de guerra, o julgamento de Nuremberg foi meramente declaratório do já existente no Direito Internacional. A afirmaçáo do Tribunal de que o desaparecimento forçado constitui também um crime contra a humanidade, no entanto, representou um marco no enfrentamento à referida violação de Direitos Humanos.

Encontra-se, assim, nos julgamentos de Nuremberg sobre o Decreto Noite e Neblina, por meio da aplicação das normas de Direito Internacional Humanitário, o embriāo da proteção das pessoas contra o desaparecimento forçado (Finucane, 2010, p. 181).

O entendimento do papel da prática de dentro do regime nazista é fundamental para o estudo latino-americano, na medida em que ambos se apresentam como totalitários. Dessa forma, várias características se repetem nas ditaduras latino-americanas e as peculiaridades deste momento histórico se mostram com maior clareza.

Durante a Segunda Guerra, é possível notar que o desaparecimento forçado era um instrumento utilizado pelo Estado contra indivíduos de outros territórios - no caso os ocupados pelos nazistas - ou contra os não considerados cidadáos daquele Estado. O Estado, porém, ainda não utilizava tal prática contra seus próprios nacionais.

${ }^{2}$ Convenção de Haia sobre as Normas e Costumes da Guerra em Terra de 18 de outubro de 1907. 
Foi nas décadas de 60 e 70 na América Latina que esse fenômeno ocorreu. Dentro do novo cenário apresentado, os Estados utilizam dessa prática contra seus próprios cidadãos. Países como Argentina (1966 e 1976), Chile (1973), Uruguai (1973) e Brasil (1964) passaram por períodos de ditadura, apoiados em uma utilização sistemática do desaparecimento forçado.

\section{O DESAPARECIMENTO FORÇADO E AS DITADURAS NA AMÉRICA LATINA}

Entender a lógica da utilização do desaparecimento forçado desencadeado na América Latina requer um breve apanhado histórico. $\mathrm{O}$ objetivo é procurar compreender a justificativa do emprego dessa prática pelos Estados e, por meio disso, identificar o perfil das vítimas dos desaparecimentos nessa região.

Para isso, é importante entender o contexto que justifica a adoção em massa dos regimes de exceção nos países latino-americanos. Nas décadas de 60 e 70 nada menos do que 14 países da região se encontravam nessa situação.

Nessa época, observa-se um grande crescimento da mobilização dos movimentos sociais na América Latina; aumentam as reivindicaçóes no plano político, como a ampliação do direito de voto e o aperfeiçoamento do sistema democrático, e também no plano econômico-social, como a melhor distribuição da propriedade da terra e da riqueza produzida em suas naçóes, além da ampliação de direitos trabalhistas (Mendes, 2013, p. 7).

Nesse contexto, destaca-se a ocorrência da revolução Cubana de 1959, quando, após mais de três anos de luta contra o governo de Fulgêncio Batista, apoiado pelos Estados Unidos, segmentos oriundos das camadas médias, organizadas em torno do Movimento 26 de Julho, lideraram uma ampla frente de oposição armada contra a ditadura (Mendes, 2013, p. 8).

Tal movimento chegou ao poder, resultando em uma série de reformas que alteram profundamente o sistema de distribuiçáo de riquezas; fato que levou à sinalização de que estes movimentos também poderiam eclodir na América do Sul. 
Foi como resposta a essa tendência que as ditaduras começaram a se instaurar nos países da América Latina. Brasil (1964), Argentina (1966), Chile (1973) e Uruguai (1976), entre outros países, passaram por ditaduras militares ${ }^{3}$ durante essa época.

A chegada ao poder, bem como a base para a manutenção dos regimes de exceção na América Latina, encontram seu cerne na chamada Doutrina da Segurança Nacional (DSN).

A DSN surgiu ao longo dos dez anos posteriores à Segunda Guerra Mundial como um corpo de princípios elaborados por civis norte-americanos do National Security People. O objetivo era determinar o novo papel dos Estados Unidos no cenário pós-Segunda Guerra, pautado no entendimento de que a União Soviética apresentava à época planos de expansão do comunismo. ${ }^{4}$

Assim, a Doutrina modificou a lógica da política externa norte-americana. O isolacionismo dos períodos anteriores é afastado em razão da disseminação de uma perspectiva de “real ameaça comunista”. É respaldado, então, um novo papel que o governo buscava exercer no mundo: a consolidaçáo de uma supremacia.

A Doutrina foi transmitida aos militares norte-americanos por meio do National War College. Gradativamente uma política de contenção do comunismo, estabelecida pelos EUA, ao longo das décadas de 50 e 60, propagou-se para a Europa, Ásia e América Latina.

Nessa última região, difundiu-se sob duas formas. Primeiramente, a partir das escolas militares que se destinavam a "melhor prepararem" os oficiais latino-americanos no combate ao comunismo; e, também, por meio dos acordos militares

\footnotetext{
3 Apesar de lideradas pelas Forças Armadas, nota-se, nos países uma coalização composta também por membros da sociedade civil e apoiada por partidos de direita, como o Brasil a Argentina e o Uruguai.

${ }^{4} \mathrm{Na}$ época se conjecturava que os movimentos comunistas grego e turco estavam sendo manipulados pelos soviéticos, além disso, a situação de destruição existente na Europa no pós-guerra poderia possibilitar a disseminação do comunismo (LinkINK, 1965, p. 165).
} 
multilaterais e bilaterais consolidados principalmente nas Conferências do México e do Rio de Janeiro, além de Tratados, como o Interamericano de Assistência Recíproca (Tiar), ${ }^{5}$ por exemplo.

Como esclarece Mendes (2013, p. 12), os militares tinham a concepção de que a estratégia soviética de propagação do comunismo aproveitava-se dos conflitos coloniais e dos problemas do Terceiro Mundo para estimular a subversão e o aparecimento de conflitos internos, com o objetivo final de conquista do poder por parte dos movimentos comunistas locais.

Dessa forma, foi na América Latina que a Doutrina da Segurança Nacional ganhou sua potencialização máxima. Apropriando-se e adaptando ideias preexistentes, como o anticomunismo latente em território latino-americano (Mendes, 2013, p. 13), torna-se possível a consolidação da base ideológica que sustenta as ditaduras.

Assim, a Doutrina de Segurança Nacional mostra-se um instrumento de dominação dos Estados Unidos pelo mundo, buscando eliminar a ideologia comunista dentro dos países americanos.

Para Valdés (1980), a pretensão norte-americana com a difusão da Doutrina não estaria somente na contenção do comunismo, mas também na defesa dos interesses vinculados ao capital das multinacionais norte-americanas em associação com uma burguesia vinculada a esses setores.

Rouquié (1984, p. 174) pondera que tal doutrina não foi imposta de fora, mas sim aceita, isto é, na maior parte dos países essa ideologia simplesmente criou seu próprio espaço. A colaboração militar dos Estados Unidos foi conscientemente buscada pelos Estados maiores latino-americanos.

5 Celebrado em 1947 na cidade do Rio de Janeiro, o Tiar é um Tratado de defesa mútua entre diversos países americanos. Ratificado por 22 países das três regióes do Continente Americano, este documento visava a unir os países da área contra eventuais ataques, estando cada um dos assinantes comprometidos, a partir de então, com a defesa dos parceiros signatários. 
Coadunando com tal pensamento, Mendes (2013, p. 36) afirma que mesmo sendo oriunda de fora, a DSN foi difundida por militares e civis - argentinos, chilenos, brasileiros e uruguaios -, não porque tenham sido manipulados por forças externas, ou pela classe militar, mas foi buscado também avidamente pelas elites da sociedade política e da sociedade civil.

De qualquer forma, é importante notar que a tentativa de conter a chamada "ameaça comunista" dentro dos países na América Latina traz consigo a disseminação de uma nova concepção de guerra. A chamada "guerra revolucionária ou insurrecional" seria a técnica que visava a propagar o caos e a desordem por meio de uma ação indireta com o objetivo de diminuir, ou mesmo eliminar, a capacidade de sobrevivência das nações capitalistas.

Sob essa ótica, a União Soviética estaria buscando instaurar dentro dos países um clima de caos e terror, para, dessa forma, obter seu controle. Tal fato serviu de justificativa para a necessidade de uma ação enérgica contra a chamada "ameaça terrorista".

Essa resposta contrarrevolucionária se divide em duas vias principais (Mendes, 2013, p. 15): a identificação e eliminação dos simpatizantes do comunismo e o extermínio do núcleo central da oposição subversiva. Essas medidas deveriam ser acompanhadas do desenvolvimento de açóes cívicas que buscariam retirar a população da órbita de influência comunista.

É possível perceber o papel da DSN também em uma comparação com o regime totalitário do nazismo. Nesse sentido, tem-se que no nazi-fascismo a política funciona a partir do binômio "amigo-inimigo", quando o segundo é entendido como um estrangeiro que deve ser combatido. Nesse contexto, a função do Estado seria a identificação e a eliminação deste inimigo.

A mesma lógica pode ser utilizada dentro do regime instituído pela Doutrina de Segurança Nacional, em que o estado de emergência passa a ser uma normalidade diante da necessidade de "extirpação do mal". Aplica-se a ideia de que o inimigo interno não é proveniente do povo, na medida em que o "verdadeiro povo" é aquele que tem uma correta noção dos objetivos nacionais (Borges, 2003, p. 30). 
Nesse sentido, adota-se a teoria de que o inimigo do país não era mais externo, mas interno. Já não se tratava de preparar o país para uma guerra tradicional, um Estado contra outro. $\mathrm{O}$ inimigo pode estar em qualquer lugar dentro do próprio país, "disfarçado" como um nacional. Para atender a este novo desafio, fazia-se urgente projetar um novo aparato repressivo.

A diferença básica nos dois contextos - nazismo e ditaduras latino-americanas - refere-se ao que se considera inimigo-alvo da repressão estatal. No caso das ditaduras, esse indivíduo é um cidadão nacional do próprio Estado. Ou seja, o que o diferencia dos outros são suas opções ideológicas.

Nesse novo contexto, o alvo dos desaparecimentos seria os indivíduos que representassem perigo à segurança nacional, os quais difundiam as ideias comunistas e recebiam a denominação de subversivos.

O terror se torna, então, a principal forma de combate a esse "inimigo interno", e é desencadeado por meio de detençôes arbitrárias, execuções extrajudiciais e desaparecimentos.

O desaparecimento forçado foi amplamente usado nas ditaduras latino-americanas. Os primeiros relatos da prática dentro dessa nova perspectiva são oriundos do conflito armado interno iniciado na década de 60, na Guatemala. Segundo apurou a Comisión para el Esclarecimiento Histórico, o número de pessoas desaparecidas no país gira em torno de $45.000,{ }^{6}$ incluindo líderes sindicais, população indígena rural e líderes estudantis ${ }^{7}$.

Após isso, a utilização sistemática do desaparecimento forçado dentro das ditaduras latino-americanas se estendeu para países como El Salvador, Chile, Uruguai, Argentina, Brasil, Colômbia, Peru, Honduras, Bolívia, Haiti e México (Alflen, 2010, p. 214), o que chama a atençáo da comunidade internacional.

${ }^{6}$ ONU, Press Release. "UN Working Group on Disappearances Concludes Visit to Guatemala." September 25, 2006.

7 Ver: National Security Archive Electronic Briefing Book no 11. "U.S. Policy in Guatemala 1966-96." National Security Archives. Disponível em: <www.gwu.edu/ nsarchiv/NSAEBB/NSAEBB11/docs/>. 
Em âmbito global, a Assembleia Geral da ONU, por meio da Resolução 33/173 de 20 de dezembro de 1978, declara sua profunda preocupação pelos informes procedentes de diversas partes do mundo com relação ao desaparecimento forçado ou involuntário de pessoas, solicitando aos governos que garantissem que suas autoridades ou órgáos encarregados da segurança e do cumprimento da lei, tivessem responsabilidade jurídica pelos excessos que conduzissem a desaparecimentos forçados ou involuntários. ${ }^{8}$

Uma preocupação que resultou na adoção de um documento específico em torno da matéria: a Declaração sobre a Proteçẫo de Todas as Pessoas contra os Desaparecimentos Forçados. No âmbito da OEA, a Comissão Interamericana de Direitos Humanos (CIDH), passou a dedicar especial atençáo à prática de desaparecimentos forçados em seus relatórios sobre o Chile na década de 70. Apesar de repetidos apelos da CIDH, a Assembleia Geral da OEA não conseguiu adotar medidas efetivas até a Resolução de 1979 sobre o Chile, na qual declarou que "a prática de desaparecimentos é uma afronta à consciência do Hemisfério" (Rody; Gonzalez, 1997, p. 367).

No mesmo ano, a Assembleia Geral da OEA “ordenou àqueles estados em que as pessoas tinham desaparecido que se abstenham de promulgar ou aplicar leis que podem tornar difícil a investigação de tais desaparecimentos" (Rody; Gonzalez, 1997, p. 367).

Tal preocupação, somada ao intenso trabalho da $\mathrm{CIDH}$, resultou na adoção de norma específica sobre a prática também em âmbito regional: a Convenção Interamericana sobre Desaparecimento Forçado de Pessoas, do ano de 1994.

Dentro do âmbito interno dos países, porém, não se verifica qualquer esforço para a tipificação do desaparecimento forçado. A ideia de identificar tal prática como crime dentro dos Estados latino-americanos, em um contexto de violaçóes sistemáticas patrocinadas pelos próprios Estados, parece obviamente incoerente.

8 Preâmbulo da Declaração Sobre a Proteção de Todas as Pessoas Contra os Desaparecimentos Forçados da ONU. 
Uma vez que o desaparecimento forçado de pessoas é prática utilizada como forma de eliminação da oposição, como já explicitado, qualquer passo, no sentido de criminalizar tal violação em âmbito interno, se choca com os interesses de manutenção do poder das ditaduras.

Isso se torna claro na definição adotada pela Convenção Interamericana sobre Desaparecimento Forçado de Pessoas que cita "agentes do Estado" como sujeitos ativos da violação. Dessa forma, a discussão de tipos penais de desaparecimento forçado dentro dos países se torna inócua no período das ditaduras.

\section{DESAPARECIMENTO FORÇADO E A TRANSIÇÃO DEMOCRÁTICA NA AMÉRICA LATINA}

Nas décadas de 80 e 90, após o período de sistemáticas violaçôes de Direitos Humanos ocorridas durante as ditaduras latino-americanas, o cenário começa a mudar. Nessa época, por, entre outros motivos, uma forte atuação dos organismos internacionais, a conjuntura política latino-americana caminha para a democracia.

Países como Brasil, Argentina, Chile, Paraguai, Uruguai, Peru e Honduras, entre outros, passam por um período de transição de regimes autoritários para a democracia, permitindo o surgimento de novos debates em torno das violaçôes dos Direitos Humanos.

Nesse momento, a preocupação é iniciar uma nova era democrática baseada no respeito aos Direitos Humanos. Assim, quando uma sociedade decide deixar para trás um passado de abuso e recomeçar sob a égide dos princípios democráticos e do respeito aos Direitos Humanos, são os mecanismos de Justiça de Transição que auxiliarão no fortalecimento desse processo.

Em um conceito amplo, ${ }^{9}$ justiça transicional pode ser entendida como o esforço para a construçáo da paz sustentável após um período de conflito, violência em massa ou violação sistemática dos Direitos Humanos (Van Zyl, 2011, p. 47).

9 Em atenção aos processos transicionais que se deram ao longo da História, não parece prudente adotar um conceito de justiça de transiçáo hermeticamente fechado, na medida em que a área da eficácia dessa define-se de acordo com as características geopolíticas e históricas de determinado contexto. Além disso, não é objetivo do presente estudo se aprofundar no tema, apenas mostrar sua relaçáo com a prática de desaparecimento forçado. 
Segundo o magistrado espanhol Baltasar Garzón:

a história da impunidade em todos os povos é a história da covardia dos que a geraram, mas também dos que a consentiram ou a consentem posteriormente. Em todas as hipóteses a história está marcada por grandes discursos de justificação e de chamadas à prudência de modo a não se romper os frágeis equilíbrios conseguidos em troca da não exigência de responsabilidades dos perpetradores ou que a referida exigência se realize com moderação. Da mesma forma, abundam discursos justificativos (2005, p. 172).

No marco das Naçóes Unidas, o conceito da justiça de transição compreende a totalidade dos processos e mecanismos relacionados aos esforços de uma sociedade por se reconciliar com uma herança de graves violaçóes cometidas no passado, a fim de assegurar a responsabilização, a administração da justiça e a reconciliaçáo. Esses processos podem compreender mecanismos judiciais e não judiciais, com diferentes níveis de participação internacional e julgamentos individuais, reparaçóes, busca da verdade, reformas institucionais, verificação de antecedentes, demissóes, ou uma combinação destes. ${ }^{10}$

A justiça de transição pode, então, ser entendida como o conjunto de esforços jurídicos e políticos para o estabelecimento ou restabelecimento de um sistema de governo democrático fundado em um Estado de Direito, cuja ênfase não recai apenas sobre o passado, mas também em uma perspectiva de futuro, tendo como objetivo investigar a maneira pela qual sociedades, marcadas por passados de abusos de Direitos Humanos, atrocidades massivas ou diferentes formas de traumas sociais, buscam trilhar um caminho de mais democracia ou apenas de mais paz (Santos, 2010, p. 43).

Deve-se levar em consideração o fato de que, com frequência, as estratégias da justiça transicional são desenvolvidas em contextos nos quais a paz é frágil ou os perpetradores conservam um poder real, exigindo, assim, um equilíbrio cuidadoso entre as exigências da justiça e a realidade do que pode ser efetuado a curto, médio e longo prazos.

\footnotetext{
${ }^{10}$ Vide "Estado de direito e a justiça de transição nas sociedades que sofrem ou tenham sofrido conflitos", documento do Conselho de Segurança das Naçóes Unidas S/2004/619 (3 de agosto de 2004), p. 4.
} 
Ainda que não se adote um modelo único que se aplique a todos os casos, em razão das especificidades de cada contexto transicional, a justiça de transição apresenta alguns pilares que a sustentam. São eles: o direito à justiça, o direito à reparação e o direito à verdade (Sikkink; Walling, 2007). ${ }^{11}$

Quanto ao primeiro ponto, reconhece-se que o julgamento dos responsáveis por graves violaçóes dos Direitos Humanos é uma parte crítica de qualquer esforço para confrontar um legado de abuso. Tal medida, porém, é fundamental para evitar violaçôes futuras, dar uma resposta às vítimas, bem como impulsar o processo de reforma das instituiçóes governamentais.

Os julgamentos não devem ser vistos somente como expressões de um anseio social de retribuição, dado que também desempenham uma função vital quando reafirmam publicamente normas e valores essenciais cuja violação implica sançôes.

Os processos também podem auxiliar a restabelecer a confiança entre os cidadãos e o Estado, demonstrando àqueles, cujos direitos foram violados, que as instituiçóes estatais buscam proteger e não violar seus direitos. Isso pode servir de alento às vítimas e diminuir seus sentimentos de raiva, marginalização e afronta.

Nesse sentido, a punição dos agentes responsáveis pelos desaparecimentos forçados nas ditaduras é vista como medida essencial para firmar as bases para uma transição sólida para as democracias.

Tal medida, no entanto, encontra como empecilho para sua realização as leis de anistia editadas pelos Estados. Foi uma prática recorrente nas ditaduras latino-americanas à adoção de leis que tinham como objetivo impedir a persecução penal de crimes praticados pelo Estado.

Dessa forma, tem-se a questão da impunidade no momento da abertura dos regimes ditatoriais para a democracia em boa parte dos países da América Latina onde ocorreram desaparecimentos, e um dos aspectos que interferiu fortemente na persecução penal dos que realizaram desaparecimento forçados, foi a promulgação de leis de anistia.

${ }^{11}$ No mesmo sentido ver PiovesanIOVESAN (2012). Para esta, acrescentam-se também as reformas institucionais, sobretudo as endereçadas ao aparato de segurança e Forças Armadas, sendo inaceitável que perpetradores de atrocidades no passado permaneçam com o monopólio das armas no país. 
As chamadas lei de autoanistia caracterizam-se quando a norma é criada pelo mesmo governo que patrocinou as violaçóes objeto da anistia. Trata-se, assim, não de uma decisão isenta, imparcial, mas visivelmente para atender seus próprios interesses (Swensson Junior, 2007, p. 171).

$\mathrm{Na}$ experiência latino-americana a adoção dessas leis foi uma constante nos períodos de transiçáo, o que demonstra que uma significativa parcela de poder político permanece nas mãos dos que praticaram o desaparecimento forçado, bem como seus apoiadores. ${ }^{12}$

Dos 19 países que passaram por transição na época, 16 utilizaram leis de anistia, ${ }^{13}$ sendo todas objeto de consideração posterior por tribunais - tanto nacionais quanto a própria CorteIDH - por não permitirem a punição dos responsáveis por violaçōes de Direitos Humanos.

Com relação ao direito à reparação, esse compreende a indenização das vítimas pelos danos causados pelo Estado. Seu objetivo central é eliminar, na medida do possível, as consequências do ato ilícito praticado e, assim, restaurar a situação ao status quo que teria existido se tal ilicitude não houvesse ocorrido.

A análise da situação interamericana permite inferir que, frequentemente, os direitos das vítimas são negligenciados e colocados abaixo de outras prioridades, na medida em que muitas vezes se favorece prioritariamente o fim do conflito, ou seja, as vítimas carecem de poder de barganha entre aqueles que negociam a transição, por não representarem ameaça à estabilidade que se almeja conquistar durante o processo.

Afirma-se aqui, porém, a importância do direito da reparação às vítimas como forma de estabelecer as bases da confiança da população no Estado recém-democrático.

${ }^{12}$ Lei de anistia (Lei n. 6683/79) no Brasil; Lei do Ponto Final (Lei n. 23.492/86) e da Obediência Devida (23.521/87) na Argentina; Lei n. 26.479 no Peru; Decreto Lei n. 2.191 no Chile; Lei n. 15.848 no Uruguai, entre outros.

${ }^{13}$ Apenas Guiana, Granada e Paraguai não adotaram leis de anistia (Sikkink; Walling, 2007, p. 435). 
Quando se fala em reparação de direitos que foram violados por práticas como o desaparecimento forçado, deve-se olhar a questáo sob perspectiva mais ampla. As reparaçôes têm também um caráter simbólico e, além disso, têm como base a ideia de não repetição.

Desse modo, entre as formas de reparação cita-se: pedidos de desculpa oficiais, a busca e identificação dos restos dos mortos e desaparecidos, a punição dos responsáveis e a revelação pública da verdade.

Conforme esclarece Facio Lince (2008, p. 6), a verdade sobre os fatos ocorridos leva os familiares, que ainda mantinham a esperança da volta do desaparecido, a se confrontarem com a realidade e, assim, iniciar seu processo de luto.

Nesse sentido, a verdade, apesar de não apresentar a materialidade de um cadáver, pode ser entendida como um meio de reparação muito importante, na medida em que sacia, mesmo que minimamente, a angústia das famílias.

Por outro viés, a divulgação da verdade aos familiares das vítimas, além do caráter simbólico, também possibilita a busca por justiça. A revelação da verdade permite que o agressor saia do campo da onipotência - típica de agentes amparados por uma política de desaparecimento utilizada de forma institucionalizada pelo Estado - dando às famílias o alento de afastar o sentimento de impunidade.

No que diz respeito ao direito à verdade, este se constitui como umas das bases para a construção de um Estado democrático. Perrone-Moisés assinala a importância e a amplitude desse direito ao afirmar que:

$\mathrm{O}$ direito à verdade visa ao conhecimento e ao reconhecimento. O conhecimento consiste na verdade dos fatos que, a partir da vivência acumulada, já não pode ser negada. O reconhecimento, a seu turno, é uma espécie de transformação que sofre a verdade histórica, quando assumida de forma oficial pela sociedade e pelo Estado. Trata-se de impedir que se possam negar determinados fatos relacionados a atrocidades cometidas, a exemplo do que ocorre com o "negacionismo", no Holocausto e, em muitos países da América do Sul, no que se refere aos abusos não reconhecidos pelas ditaduras militares (2009, p. 89). 
Coadunando com as reflexóes, observa-se duas perspectivas para a compreensão do direito à verdade (Naqvi, 2006). Uma se refere às violaçóes individuais de Direitos Humanos, exigindo, assim, respostas específicas para cada situação.

A outra diz respeito às violaçóes massivas desses direitos - frequentemente fruto de práticas sistemáticas de repressão utilizadas por Estados. Nesse caso, as medidas devem ser mais amplas com o objetivo de revelar as causas/razóes de tais violências, como, por exemplo, por meio de comissóes da verdade e açóes da comunidade internacional expressas em resoluçóes da Assembleia Geral e do Conselho de Segurança (Naqvi, 2006, p. 260).

Com essas reflexóes, pode-se entender que o direito à verdade tem uma perspectiva individual - o direito de uma vítima ou familiar de saber o que de fato aconteceu - e também coletiva - relativa à sociedade em geral e relacionada com a memória de um país.

Confrontando-se tais perspectivas com o crime de desaparecimento forçado, é possível notar que a primeira - individual - pode ser entendida como uma forma de reparação às vítimas (familiares), que anseiam por saber o que ocorreu com seu ente desaparecido.

$\mathrm{Na}$ segunda perspectiva, a verdade caminha no sentido de se evitar que tal prática volte a ocorrer, mantendo-se viva na memória de uma sociedade os danos causados pela utilização massiva do desaparecimento forçado pelo Estado a fim de se evitar retrocessos, na medida em que "direitos futuros demandam que uma sociedade aprenda com os abusos do passado" (Naqvi, 2006, p. 257).

Dessa forma, o direito à verdade, para as vítimas e seus familiares, resulta na obrigação do Estado de fornecer todas as informaçóes sobre as circunstâncias em que os desaparecimentos ocorreram. Para a sociedade em geral, cabe ao Estado revelar as informaçóes relativas às razóes que levaram à prática, assim como as circunstâncias que a motivaram, com o objetivo de desenvolver açóes para a compreensão e reconciliação.

Reconhecida a existência de tal direito, é importante identificar os instrumentos para efetivá-lo. A História recente demonstra que um dos mais eficientes têm sido a instituição de Comissóes da Verdade. Essas comissóes geralmente são 
temporárias (duram em média 2 anos), são oficialmente autorizadas pelo Estado, não têm caráter judicial e normalmente são criadas em um momento de transição política (Freeman; Hayner, 2003, p. 125).

O foco dessas Comissóes são as violaçóes de Direitos Humanos ocorridas no passado, resultando assim em um relatório final, no qual contenham suas conclusóes e recomendaçóes. A principal importância das Comissóes da Verdade é dar publicidade à voz das vítimas, podendo, assim, ser entendido como um importante meio de reparação:

Comissóes da Verdade limitam a possibilidade de negação ou trivialização das experiências das vítimas. Elas transformam o que é de conhecimento público e notório em reconhecimento oficial. [...] Na maioria dos casos, as Comissōes da Verdade também estiveram intimamente conectadas a outras estratégias transicionais, tais como a persecução de perpetradores de violaçôes de Direitos Humanos ou de criminosos de guerra, dando início a significativas reformas institucionais (Bickford, 2007, p. 996-997).

As comissôes da verdade são instrumentos importantes no processo de transição democrática em países como Chile, Argentina e, recentemente, foi criada no Brasil. ${ }^{14}$

Pela análise dos princípios que norteiam a Justiça transicional, nota-se que a prática do desaparecimento forçado no momento da abertura da democracia na América Latina, nesse período de transição, é considerada de uma forma muito mais abrangente.

A abertura política, mesmo que ainda não de maneira ideal, permite questionamentos que vão além do amparo às vítimas diretas, mas alcançam também formas mais amplas de reparação e discussão dos efeitos profundos causados pela

${ }^{14}$ Criada pela Lei n. 12528/2011 e instaurada em maio de 2012, a Comissão Nacional da Verdade buscou apurar e esclarecer as graves violaçóes de Direitos Humanos ocorridas durante a ditadura militar brasileira. Seu relatório final, entregue na data de 10 de fevereiro de 2014, contabiliza 434 mortos ou desaparecidos políticos, além da indicação de mais de 300 nomes de agentes públicos e pessoas a serviço do Estado possivelmente envolvidas nas violaçóes. (Fonte: Comissão Nacional da Verdade. Disponível em: <http://www.cnv.gov.br/>). 
utilização sistemática do desaparecimento forçado. Nesse momento, o grande desafio pode ser resumido em dois pontos principais: a punição dos responsáveis pela prática e a divulgação da verdade histórica sobre o ocorrido.

\section{DESAPARECIMENTO FORÇADO E A CONSOLIDAÇÃO DAS DEMOCRACIAS NA AMÉRICA LATINA}

Desde a 2a Conferência Mundial de Direitos Humanos, realizada em 1993 na cidade de Viena, o debate em torno dos Direitos Humanos alcançou um novo patamar. Reconhecendo o entendimento difundido pela comunidade internacional, a Declaração de Viena afirma a preocupação internacional com a promoção e proteção destes direitos.

Nesse momento, reconhece-se o direito ao desenvolvimento e, especialmente, a interdependência entre democracia, desenvolvimento e respeito aos Direitos Humanos (Alves, 2003, p. 137).

Norberto Bobbio afirma a interdependência entre os conceitos de democracia e Direitos Humanos ao esclarecer:

Três momentos necessários do mesmo movimento histórico: sem direitos do "homem" reconhecidos e efetivamente protegidos não existe democracia, sem democracia não existem condiçōes mínimas para a solução pacífica dos conflitos que surgem entre os indivíduos, entre grupos e entre as grandes coletividades tradicionalmente indóceis e tendencialmente autocráticas que são os Estados (2004, p. 223).

De fato, resta pacífica, atualmente, a ideia de que a democracia é, entre todas as outras formas de governo, a mais propícia ao respeito e promoção dos Direitos Humanos (Pinheiro, 2008, p. 78).

Nesse contexto, após o período das ditaduras e do período de transição dos anos 80 e $90,{ }^{15}$ a análise sobre a questão do desaparecimento forçado nas democracias recentes merece importante destaque.

${ }^{15}$ Não cabe neste estudo aferir se os requisitos de uma devida justiça de transição foram atendidos nos países. A fase de transição aqui marca um espaço temporal, como forma de demonstrar a atuação do Sistema Interamericano diante da questão. 
Como visto anteriormente, o desaparecimento forçado tem um papel crucial no sistema de repressão das ditaduras, sendo usado de forma sistemática pelos regimes militares como modo de eliminação da oposição política. Seus efeitos tiveram dimensão tal que exigem várias medidas para sua reparação e não repetição, em um esforço voltado a garantir uma devida transição democrática nos países.

É preciso reconhecer, porém, que a definição de um regime como democrático náo se mostra como suficiente razáo para se afirmar seu respeito aos Direitos Humanos. Nesse sentido, cumpre ressaltar que a democracia "não é uma panacéia capaz de, por si só, eliminar o autoritarismo e prevenir violaçôes” destes direitos (Pinheiro, 2008, p. 78).

É uma ilusão considerar que todas as contradições foram solucionadas na Conferência Mundial sobre Direitos Humanos de Viena, em 1993, na qual, na sua Declaração e Programa de Ação, a democracia figura como o regime que mais tende a proteger os Direitos Humanos.

Usando o exemplo da América Latina, afirma Paulo Sérgio Pinheiro:

Decerto, a democracia tende a promover os direitos humanos com maior facilidade, contudo, tanto em regimes democráticos consolidados, quanto naqueles recém-instaurados, ela não representa necessariamente uma garantia contra violaçôes de direitos humanos. No hemisfério sul, as transições políticas da ditadura para a democracia têm, em grande medida, mantido o status quo e não garantido uma mudança concreta. $\mathrm{Na}$ América do Sul e no Leste Europeu, democracias ocultam, com frequência, a opressão sofrida pela parcela da população economicamente mais desfavorecida, a corrupção de políticos e agentes estatais e a cumplicidade de ambos com o crime organizado (2008, p. 78).

Isso pode ser visto ao se analisar alguns dados estatísticos relevantes. Cinco dos dez países com maiores índices de desigualdade estão localizados na América Latina. Dez dos 20 países com maiores taxas de homicídio no mundo são latino-americanos.

Piovesan (2014) resume o cenário ao afirmar: 
A região ainda convive com as reminiscências do legado dos regimes autoritários ditatoriais, com uma cultura de violência e de impunidade, com a baixa densidade de Estados de Direito e com a precária tradição de respeito aos direitos humanos no âmbito doméstico (p. 143).

Nesse sentido, o grande desafio nas novas democracias da América Latina é que, embora a maioria das garantias políticas tenha sido restabelecida, os direitos civis, econômicos e sociais da maior parte da população da região ainda são continuamente desrespeitados.

O Estado assume uma nova postura ante as violaçóes. Se, no momento da ditadura, o próprio Estado é quem patrocina e sistematiza, por meio do seu aparelho repressivo, a violação em massa dos Direitos Humanos de seus nacionais, na democracia este apresenta uma postura omissa diante destas violaçóes.

Dessa forma, o que se verifica nas democracias é que a responsabilidade do Estado perante as violaçóes de Direitos Humanos no seu território podem ser verificadas muito mais vezes pela sua "não ação" na defesa e promoção dos direitos de seus cidadãos.

No caso da prática do desaparecimento forçado, esta assume novas formas no período democrático. Se já não é uma maneira de repressão estatal amparada por uma Doutrina "DSN" e utilizada por agentes de modo quase que oficial, passa a ser adotada por milícias que atuam nessa nova conjuntura.

A exemplo de outras formas de violação de Direitos Humanos derivadas de períodos autoritários, como a tortura, a prática muda o seu alvo. Nas democracias recentes na América Latina quem se encontra mais facilmente em situaçóes de violação de Direitos Humanos são os marginalizados.

Assim, as vítimas, na atual conjuntura, já não são identificadas pela sua opção ou oposição política, mas pela sua situação de estar à margem de uma sociedade caracterizada pela desigualdade social e violência sistêmica, sendo o Estado omisso no ato de sua proteção. Junte-se a isso, resquícios dos tempos autoritários ainda entranhados nas polícias, que têm forte caráter de militarização. 
A omissão estatal também se reflete na impunidade com relação à violação de desaparecimento forçado, fato que se mostra como um resquício do desafio enfrentado nos períodos transicionais, como a edição de leis de autoanistia.

Nas democracias recentes, a não punição dos responsáveis por violaçôes de Direitos Humanos, além de enfraquecer as democracias, estabelece uma relação de desconfiança entre a população e as instituiçóes do Estado.

Kathryn Sikkink e Carrie Both Walling (2007, p. 427-445), em seu estudo sobre o impacto dos julgamentos de Direitos Humanos na América Latina, constataram que, nos países onde agentes públicos que cometeram violaçôes durante as ditaduras foram condenados, a cultura de respeito a tais direitos é significativamente mais presente do que os que se furtaram a realizar tal acerto de contas com o passado autoritário.

Segundo as autoras, difícil se faz construir um Estado de Direito ignorando graves violaçôes de Direitos Humanos e fracassando em responsabilizar agentes governamentais do passado e do presente, na medida em que os cidadãos comuns passam a ter uma relação de desconfiança com o sistema legal (Sikkink; Walling, 2007, p. 441).

Nesse sentido, nota-se uma ineficiência dos órgãos de Justiça nas democracias da América Latina, na medida em que estes não logram êxito em punir as violaçóes de Direitos Humanos de forma eficaz. De fato, em poucos países se abriram processos penais contra os responsáveis pelas violações, e, mesmo nestes, muito recentemente. ${ }^{16}$

No caso do desaparecimento forçado, percebe-se a importância da adoção de um documento específico que trate da temática. Nessa direção, a Comissão Interamericana, por meio do relatório anual de 1986-1987, apela para os Estados-parte que considerassem a possibilidade de adoção de uma Convenção Interamericana para prevenir e punir essa prática.

${ }^{16}$ Cita-se, como exemplo, o caso argentino, no qual somente em 4 de agosto de 2006 foi condenado pela primeira vez um responsável direto pelos desaparecimentos: o ex-suboficial da Polícia Federal Argentina Julio Simón, também conhecido como “Turco Julián”, que foi condenado a 25 anos de prisão (Seoane, 2001, p. 227). 
Afirmou a CIDH que a política de desaparecimentos na América Latina foi um importante instrumento de repressão e de supressão física de dissidentes, exigindo, portanto, a adoção de medidas especiais nos âmbitos nacional e internacional, a fim de tornar essa prática extinta.

Foi somente no ano de 1994, todavia, que tal Convençáo veio a ser aprovada. Elaborada pela Assembleia Geral da Organização dos Estados Americanos em Belém do Pará, esta convenção interamericana tem como foco norteador a busca de uma resposta mais efetiva para os milhares de desaparecimentos forçados de indivíduos ocorridos durante os regimes ditatoriais na América Latina.

A Convenção Interamericana sobre Desaparecimentos Forçado de Pessoas entrou em vigor em 1996, o que claramente coincide com o processo de democratização que ocorreu na regiáo à época.

Como se nota, a adoção da Convenção ocorre quase 30 anos após a institucionalização de desaparecimentos como uma prática sistemática na América Latina. Tal fato é compreensível, como aqui já se afirmou, quando se pensa que os governos militares seriam relutantes em criminalizar uma prática considerada uma política de Estado. Nesse sentido, a aprovação e adoção de tal Convenção somente se torna possível no contexto das democracias recentes.

Diz o artigo 2o da Convenção:

Art. 2. Para os efeitos desta Convenção, entende-se por desaparecimento forçado a privaçáo de liberdade de uma pessoa ou mais pessoas, seja de que forma for, praticada por agentes do Estado ou por pessoas ou grupos de pessoas que atuem com autorização, apoio ou consentimento do Estado, seguida de falta de informação ou da recusa a reconhecer a privação de liberdade ou a informar sobre o paradeiro da pessoa, impedindo assim o exercício dos recursos legais e das garantias processuais pertinentes.

A partir da leitura do dispositivo, tem-se a noção da preocupação com relação à postura do Estado nesse tipo de violação. A figura do sujeito ativo contém o Estado agindo diretamente, por meio de seus agentes, e também ressalta a atitude omissa mediante "autorização, apoio, ou consentimento". 
Além disso, ao classificar o desaparecimento como a "privação de liberdade", estabelece como bem jurídico protegido a liberdade pessoal prevista no artigo $7{ }^{\circ}$ da Convenção Americana. ${ }^{17}$ Soma-se como elemento da conduta a ausência de informação sobre o paradeiro do desaparecido, que também pode ser entendida como uma omissáo do Estado.

Por fim, o dispositivo explicita, como resultado da violação, o impedimento ao exercício dos recursos legais e das garantias processuais, direitos previstos no artigo $8^{\circ} \mathrm{da} \mathrm{CADH} .{ }^{18}$

A leitura da Convenção Interamericana permite afirmar ser esta uma clara consequência da preocupação em torno da utilização massiva e sistemática da prática como forma de eliminação da oposiçáo por parte das ditaduras latino-americanas, como já analisado anteriormente neste estudo.

${ }^{17}$ Artigo $7^{\circ}-$ Direito à liberdade pessoal 1. Toda pessoa tem direito à liberdade e à segurança pessoais. 2. Ninguém pode ser privado de sua liberdade física, salvo pelas causas e nas condições previamente fixadas pelas Constituiçōes políticas dos Estados-partes ou pelas leis de acordo com elas promulgadas. 3. Ninguém pode ser submetido à detenção ou encarceramento arbitrários. 4. Toda pessoa detida ou retida deve ser informada das razôes da detenção e notificada, sem demora, da acusação ou das acusaçôes formuladas contra ela. 5. Toda pessoa presa, detida ou retida deve ser conduzida, sem demora, à presença de um juiz ou outra autoridade autorizada por lei a exercer funçóes judiciais e tem o direito de ser julgada em prazo razoável ou de ser posta em liberdade, sem prejuízo de que prossiga o processo. Sua liberdade pode ser condicionada a garantias que assegurem o seu comparecimento em juízo. 6. Toda pessoa privada da liberdade tem direito a recorrer a um juiz ou tribunal competente, a fim de que este decida, sem demora, sobre a legalidade de sua prisão ou detenção e ordene sua soltura, se a prisão ou a detenção forem ilegais. Nos Estados-partes cujas leis preveem que toda pessoa que se vir ameaçada de ser privada de sua liberdade tem direito a recorrer a um juiz ou tribunal competente, a fim de que este decida sobre a legalidade de tal ameaça, tal recurso não pode ser restringido nem abolido. $\mathrm{O}$ recurso pode ser interposto pela própria pessoa ou por outra pessoa. 7. Ninguém deve ser detido por dívidas. Este princípio não limita os mandados de autoridade judiciária competente expedidos em virtude de inadimplemento de obrigação alimentar.

${ }^{18}$ Artigo 8 - Garantias judiciais

1. Toda pessoa terá o direito de ser ouvida, com as devidas garantias e dentro de um prazo razoável, por um juiz ou Tribunal competente, independente e imparcial, estabelecido anteriormente por lei, na apuração de qualquer acusação penal formulada contra ela, ou na determinação de seus direitos e obrigaçôes de caráter civil, trabalhista, fiscal ou de qualquer outra natureza. 
Nesse ponto, ressalta-se a importância da atuação da Corte Interamericana de Direitos Humanos, bem como a CIDH, para a definição do conceito empregado na Convenção Interamericana, bem como a importância da Convenção para os posteriores julgados da Corte. Tal relaçáo será mais bem esclarecida mais à frente do presente texto.

Outro grande desafio enfrentado pela Corte Interamericana na temática do desaparecimento forçado, com relação aos países em consolidação da democracia, diz respeito ao controle de convencionalidade. Entende-se o exame de compatibilidade entre a legislação doméstica diante dos instrumentos internacionais de Direitos Humanos, realizado pela CorteIDH (Mazzuoli, 2011, p. 73), que têm como base o previsto nos artigos $1^{\circ}$ e $2^{\mathrm{o}^{19}}$ da Convenção Americana.

Lembre-se que, atualmente, existe em âmbito interamericano documento específico que trata da violação. A Convenção Interamericana sobre o Desaparecimendo Forçado de Pessoas, de 1994, assinada por vários países latino-americanos, prevê no seu artigo 10 "d" a obrigação de "tomar as medidas de caráter legislativo, administrativo, judicial ou de qualquer outra natureza que sejam necessárias para cumprir os compromissos assumidos".

Conforme afirma Piovesan (2014, p. 151), o controle de convencionalidade deve ser realizado tanto na sua modalidade concentrada quanto difusa. A primeira exercida em âmbito regional pela Corte Interamericana, que tem a última palavra sobre a interpretação da Convenção Americana. A segunda exercida na esfera doméstica pelos tribunais nacionais, mediante a incorporação da normatividade, principiologia e jurisprudência protetiva internacional em matéria de direitos humanos no contexto latino-americano.

Especificamente com relação ao desaparecimento forçado de pessoas, a jurisprudência da CorteIDH demonstra uma preocupação constante em fazer com que os Estados-parte contenham a tipificação de tal violação como crime em seus ordenamentos internos.

${ }^{19}$ O primeiro gera a obrigação de garantir o livre e pleno exercício dos Direitos Humanos reconhecidos, e o segundo consagra o dever de adotar disposiçôes internas compatíveis com a Convenção e o dever de efetivar os direitos nela contemplados. 
Nesse sentido, no momento da consolidação das democracias recentes na América Latina, a tipificação do desaparecimento forçado como um crime no âmbito dos países é o foco principal da atuação da Corte Interamericana, buscando-se que as legislaçóes internas dos Estados apresentem consonância com a CADH.

Ao exercer o controle de convencionalidade, a Corte busca não somente estabelecer a obrigatoriedade de tipificaçáo no ordenamento interno, mas também esclarece os elementos centrais que devem conter no tipo penal adotado no país.

Dessa forma, percebe-se a urgência em se fazer cumprir de forma eficaz as disposiçóes previstas em âmbito supranacional na esfera do direito interno dos países, como forma não apenas de se punir as violaçóes do passado, mas evitar violaçóes que ocorrem no contexto atual em razão da atitude omissa dos Estados.

Em atençáo a essas questóes, afirma-se que o grande desafio nas democracias recentes reside na afirmação dos Direitos Humanos como base para o estabelecimento de Estados de Direito. Com vistas a evitar violaçóes, é preciso que a questão da garantia e proteçáo de direitos seja vista de forma ampla.

\section{CONSIDERAÇÕES FINAIS}

A partir do estudo, é possível ter uma visão completa sobre o fenômeno do desparecimento forçado na América Latina. Amparado pela Doutrina de Segurança Nacional, a prática do desaparecimento forçado foi uma das formas mais utilizadas de repressão em razão da amplitude dos efeitos que causa, como o sentimento de insegurança e angústia aos familiares e amigos.

Ao adotar a ideia do "inimigo interno", o poder repressivo das ditaduras utiliza a prática, contra seus próprios nacionais, como forma de eliminar a oposição política e a consequente manutenção dos regimes. Seu uso frequente e massivo, passa a chamar a atenção da comunidade internacional em torno do tema.

No período de transição democrática, a temática do desaparecimento ganha novos contornos. Erguem-se como principais desafios a uma devida justiça de transição - amparada nos pilares do direito à Justiça, à reparaçáo e à verdade - as leis de anistia. 
A adoção por vários governos na América Latina das chamadas "autoanistias" representaram um grande empecilho para a punição dos responsáveis pelos desaparecimentos, sendo negado, assim, o direito à Justiça aos familiares.

Quanto ao direito à verdade, este assume uma dimensão pública importante no contexto transicional, diferenciando-se da mera informaçáo sobre o ocorrido às vítimas e familiares, mas focando-se no estabelecimento de uma memória coletiva com o fim de se evitar retrocessos.

A consolidação democrática enfrenta como desafios resquícios da prática massiva do desaparecimento. Tendo-se como pano de fundo o contexto latino-americano de grande desigualdade e violência, resta claro que a mera transição para a democracia não tem o condão de automaticamente garantir o respeito aos direitos humanos.

Com base nessas questôes, afirma-se que o grande desafio nas democracias recentes reside na afirmação dos Direitos Humanos como base para o estabelecimento de Estados de Direito. Com vistas a evitar violaçóes, é preciso que a questão da garantia e proteçáo de direitos seja vista de forma ampla.

Os sistemas de proteção dos direitos humanos nunca serão eficazes por completo para os excluídos, se os países não solucionarem a deficiência da legislação interna, a ineficácia do Poder Judiciário, a inoperância do aparato repressivo do Estado e o estabelecimento precário dos direitos no âmbito nacional.

É preciso o fortalecimento das instituiçôes estatais baseadas em uma cultura de respeito à dignidade humana, em sua concepção mais ampla, para que o legado da época dos desaparecimentos náo continue latente na nossa sociedade.

\section{REFERÊNCIAS}

ALFLEN, Pablo Rodrigo. El delito de desaparición forzada de personas y el Derecho penal brasileño. Revista de Derecho de la Pontificia Universidad Católica de Valparaíso, Valparaíso, Chile, v. XXXIV, p. 213-226, 2010.

ALVES, José Augusto Lindgren. Direitos uumanos como tema global. São Paulo: Perspectiva, 2003. 
ARENDT, Hannah. As origens do totalitarismo. São Paulo: Companhia das Letras, 1989.

BICKFORD, Louis. Unofficial Truth Projects. Human Rights Quarterly, Baltimore, v. 29, p. 995-1.035, 2007.

BOBBIO, Norberto. A era dos Direitos. Rio de Janeiro: Elsevier, 2004.

BORGES, Nilson. A doutrina de segurança nacional e os governos militares. In: FERREIRA, Jorge; DELGADO, Lucilia de A. Neves. O Brasil republicano: o tempo das ditaduras. Rio de Janeiro: Civilização Brasileira, 2003.

FACIO LINCE, Victoria Eugenia Diaz. Del dolor al duelo, límites alanhelo frente a la desaparición forzada. In: Affectio Societatis, v. 9, 2008.

FINUCANE, Brian. Enforced Disappearance as a Crime Under International Law: A Neglected Origin in the Laws of War. The Yale Journal of International Law. v. 35, p. 171$195,2010$.

FREEMAN, Mark; HAYNER, Priscilla. Truth-Telling. In: BARNES, Teresa; BLOOMFIELD, David; HUYSE, Luc. Reconciliation After Violent Conflict: A Handbook. Stockholm: Institute for Democracy and Electoral Assistance, 2003.

FACIO LINCE, Victoria Eugenia Diaz. Del dolor al duelo, límites alanhelo frente a la desaparición forzada. In: Affectio Societatis, v.9, 2008.

GARZÓN, Baltasar. Un mundo sin miedo. Barcelona: Plaza Janés, 2005.

LINK, Arthur S. História Moderna dos Estados Unidos. Rio de Janeiro: Zahar, 1965.

MARTIN, Sophie. The missing. In: International Review of the Red Cross. Humanitarian Debate: Law, Policy, Action. v. 84, p. 723-726, 2002.

MENDES, Ricardo Antônio Augusto de Souza. Ditaduras civil-militares no Cone Sul e a Doutrina de Segurança Nacional - algumas consideraçôes sobre a Historiografia. Revista Tempo e Argumento, v. 5, n. 10, p. 6-38, 2013.

NAQVI, Yasmin. The Rigth to the Truth in International Law: Fact or Fiction? International Review of the Red Cross, v. 88, n. 862, p. 244-272, 2006.

PERRONE-MOISÉS, Cláudia. Imunidades de chefe de Estado e crimes internacionais. 2009. Tese (Livre Docência) - Faculdade de Direito, Universidade de São Paulo (USP), São Paulo, 2009.

PINHEIRO, Paulo Sérgio. Os sessenta anos da Declaração Universal: atravessando um mar de contradiçôes. SUR - Revista Internacional de Direitos Humanos, v. 9, p. 77-87, 2008. 
PIOVESAN, Flávia. Lei de Anistia, Direito à Verdade e à Justiça: o Caso Brasileiro. In: Revista Interesse Nacional. Ano 5, v. 17, abril-junho 2012.

. Sistema Interamericano de Direitos Humanos: impacto transformador, diálogos jurisdicionais e os desafios da reforma. Revista de Estudos Constitucionais, Hermenêutica e Teoria do Direito (RECHTD) pp:142-154, 2014.

RODY, Reed; GONZALEZ, Felipe. Nunca Mas: an analysis of international instruments on "disappearances". Human rights quarterly, v. 19, p. 365-405, 1997.

ROUQUIÉ, Alain. O Estado Militar na América Latina. Rio de Janeiro: Alfa-Ômega, 1984.

SANTOS, Roberto Lima. Crimes da Ditadura Militar. Responsabilidade internacional do Estado brasileiro por violaçóes aos direitos humanos. Porto Alegre: Núria Fabris, 2010.

SEOANE, María. El dictador. Buenos Aires: Sudamericana, 2001.

SIKKINK, Kathryn; WALLING, Carrie Both, The Impact of Human Rights Trials in Latin America. In: Journal of Peace Research, Los Angeles, Londres, Nova Déli, Singapura, n. 4, p. 427-445, 2007.

SWENSSON JUNIOR, Lauro Joppert. Anistia penal: problemas de validade da lei de anistia brasileira. Curitiba: Juará, 2007.

VAN ZYL, Paul. Promovendo a justiça transicional em sociedades pós-conflito. Manual justiça de transição américa latina. In: Justiça de transição: manual para a América Latina, Brasília: Comissão de Anistia; Ministério da Justiça, 2011.

VALDÉS, Jorge Alberto Tapia. El terrorismo de Estado: la doctrina de la seguridad nacional en el Cono Sur. México (DF): Ediorial Nueva Imagen, 1980.

VITKAUSKAITÉ-MEURICE, Dalia; ŽILINSKAS, Justinas. The Concept of Enforced Disappearances, v. 2, p. 197-214, 2010.

Recebido em: 20/03/2015

Aceito em: 26/01/2016 